\title{
NOTAS CONCEITUAIS E DEFINIÇÕES DE SUPORTE ÀS POLÍTICAS PÚBLICAS PARA A AGROPECUÁRIA APÓS A CONSTITUIÇÃO FEDERAL DE $1988^{1}$
}

\author{
Gesmar Rosa dos Santos² \\ Carlos Eduardo de Freitas Vian ${ }^{3}$ \\ Lauro Mattei ${ }^{4}$
}

\begin{abstract}
1 INTRODUÇÃO
A segunda metade do século XX foi o marco da gênese e evoluçáo das políticas agrícolas no mundo, período de aprendizado do desenvolvimento de instrumentos e avaliação dos seus impactos nos mercados. Também marcou uma grande adaptação dos objetivos e correção de rumos das políticas em resposta às novas dinâmicas e temáticas, como alimentação, meio ambiente, emprego, preservação do patrimônio, entre outras.

Em larga medida, o aparato de instrumentos de políticas públicas para a agricultura foi baseado, de um lado, no arcabouço teórico da economia neoclássica, com foco nas questóes de custos, preços, alteraçôes de oferta e demanda e regulaçâo das condiçôes de comércio internacional; de outro, em pacotes tecnológicos apoiados no conhecimento agronômico e no uso intenso de insumos industriais e mecanização de lavouras, no contexto da Revolução Verde, a partir da década de 1960. As políticas de suporte aos produtores, como as de preços mínimos, estoques reguladores e tarifas de comércio internacional, vigoram por décadas nos países desenvolvidos (OECD, 2020) e são praticadas, porém em muito menor escala e em queda, no Brasil.

A partir dos anos 1990, as políticas públicas para a agricultura dos países desenvolvidos passaram a utilizar um arcabouço teórico mais amplo, com influência de outras ciências sociais aplicadas, revisando paradigmas anteriores (Stevens, 2011). Mudanças na visão de mundo sobre a dinâmica da agricultura propiciaram que o foco na propriedade monocultora proporcionasse espaço, também, ao papel da agricultura inter-relacionado com o ambiente rural.
\end{abstract}

1. DOI: http://dx.doi.org/10.38116/brua23art1

2. Técnico de planejamento e pesquisa na Diretoria de Estudos e Políticas Regionais, Urbanas e Ambientais (Dirur) do Ipea.

3. Professor da Escola Superior de Agricultura Luiz de Queiroz da Universidade de São Paulo (Esalq/USP).

4. Professor da Universidade Federal de Santa Catarina (UFSC). 
Desse modo, as políticas agrícolas passaram a reconhecer a atividade agrícola e os agricultores como parte de um lócus de produção pelo cultivo de alimentos, que presta serviços, preserva a natureza, mantém características, hábitos e culturas locais e regionais, inclusive alimentares. Entretanto, muitas dessas políticas permanecem sustentadas nos pressupostos da economia neoclássica de firma monocultora, que deve buscar eficiência, produtividade e redução de custos de produção (medidas internamente e não observando danos ambientais) para se posicionar em mercados de produtos homogêneos. $\mathrm{O}$ debate atual, no entanto, adere a paradigmas de sustentabilidade socioambiental, nos quais a agropecuária deve se pautar, além de suas funçôes tradicionais, pela redução de desigualdades, pela atenção a mudanças climáticas e ao desmatamento como condição para acesso a mercados importantes (Stevens, 2011; Belik, 2015; FAO e Unep, 2020; OECD, 2020).

No período de 22 anos decorridos entre os três últimos recenseamentos agropecuários, de 1995 a 2017, foram também marcantes as mudanças na organização social e produtiva e no amadurecimento das políticas que interferem no campo. Nesse período, as políticas têm reconhecido, embora com lacunas, as diversidades presentes no ambiente rural e nos diferentes sistemas de produção (Costa, 2009; Silva, 2015; Santos e Freitas, 2017; Sambuichi et al., 2017). Esses sistemas são descritos sob as distintas perspectivas e dimensões, refletindo a multifuncionalidade e a pluriatividade da agricultura, como retratadas em Mattei (1999), Schneider (2003a; 2003b), Schneider et al. (2013) e Silva (2015).

O debate sobre quais os tipos de políticas agrícolas os governos deveriam adotar seguiu, nos anos 1990, a interpretação corrente em outros países sobre a chamada "terceira via" do papel da agricultura na sociedade (Lowe, Buller e Ward, 2002). Os autores retratam como as vias originárias, a de avanços das teses liberalizantes dos mercados dos anos 1980 e a via do protecionismo não respondiam às necessidades e realidades das múltiplas funções da agricultura e do rural.

No Brasil, antes da estruturação das políticas vigentes para a agricultura familiar, vivenciou-se um profícuo debate acerca das dificuldades, desafios e caminhos que as políticas públicas deveriam seguir para dar suporte ao acesso à terra e demais meios de produção. A organização institucional teve também altos e baixos, incluindo: a criação do Ministério de Desenvolvimento Agrário (MDA), extinto em 2019; mudanças na extensão rural, com desmonte de estrutura vigente desde os anos 1980, sem planejamento e sem modelo de transição, como observado por Freitas e Maciente (2016); entre outros.

Sobressaíram-se o apoio ao crédito, por meio do Programa Nacional de Fortalecimento da Agricultura Familiar (Pronaf), e outras linhas para grandes e médios produtores, além de programas de menor impacto (Santos e Freitas, 2017). A defesa agropecuária seguiu trajetória de forma sólida, de modo a dar suporte à grande produção resultante em agricultura e agroindústria. Niederle, Fialho e Conterato (2014) levantam a necessidade de se retomarem conceitos "esquecidos" e análises sobre a diversidade que fomentou as políticas recentes para a agricultura familiar, como condição para possibilitar avanços.

Esse conjunto de acontecimentos, ancorado em atores sociais atuantes em seus diversos foros, deu formato às políticas agrícolas, que demandaram, até 2015 , cerca de $\mathrm{R} \$ 12$ bilhôes de gasto público por ano (Santos e Freitas, 2017), tendo reduzido, desde então, para aproximadamente R \$ 9 bilhóes. Lembrando que esse gasto se constitui de subvençôes, equalização de taxas e outros subsídios a políticas que viabilizam o crédito agrícola de mais de $\mathrm{R} \$ 250$ bilhóes anuais, a política de redução de riscos, o apoio à comercialização, a defesa agropecuária, entre outras. 
Assim, é importante trazer algumas definições e conceitos que deram suporte à boa parte das políticas públicas para a agricultura no Brasil, embora este boletim não tenha a pretensão de aprofundar esse tema, o que se pretende fazer na segunda etapa do projeto. Portanto, as definiçōes e a breve discussão feitas a seguir objetivam facilitar a compreensão do estágio atual da agricultura no Brasil e posicionar o leitor sobre os motivos de se adotar a leitura dos dados do censo agropecuário com enfoque no tema diversidade.

\section{DEBATE SOBRE 0 SUPORTE DAS POLÍTICAS AGROPECUÁRIAS A PARTIR DOS ANOS 1990}

Trabalhos como os de Lowe, Buller e Ward (2002) destacam a construção, ancorada na "terceira via", de políticas a partir de reformas da antiga Common Agricultural Policy (CAP), da União Europeia (UE). Baseada na Rural Development Regulation (RDR) e no cenário de exigências ambientais no contexto dos tratados das Naçóes Unidas, a CAP rivaliza com a corrente liberal e tendências do comércio internacional. Países da África e da Ásia, inclusive por históricos de desabastecimento, carestia e fome, em parte se inspiram nessa terceira via, o que também se reflete em políticas dos países da América Latina após os anos 1990, incluindo o Brasil. Assim, a discussão sobre a segurança alimentar emerge e se combina com teses de ajuda estatal para a agricultura e a vida no campo. Ao mesmo tempo, mantém-se o domínio do capital de base Europeia e dos Estados Unidos e posteriormente também da China, sobre a produção de insumos tecnológicos e do comércio mundo afora.

Paralelamente às múltiplas funçôes e pluriatividades da agricultura, defendidas pela terceira via, tem continuidade também o avanço do liberalismo remodelado e do protecionismo interno dos países ricos, apesar das revisōes da CAP, questão frequentemente levantada pelos países exportadores de produtos agrícolas.

A combinação desses enfoques com os avanços tecnológicos e subsídios nos países ricos induziu: i) o aumento da segurança alimentar, ainda que com produção mais cara; ii) o domínio tecnológico dos países da UE que rivalizam com os Estados Unidos na geração de patentes e produção de bens (insumos e máquinas) para a agricultura, posto hoje dividido com a China; iii) a expansão de grandes grupos (controladores dos mercados estratégicos de áreas de sementes, defensivos/agrotóxicos, seguros rurais), de origem nos mesmos países; iv) o apoio à expansão de empresas comercializadoras de commodities (traders); e v) o estabelecimento de padrôes, condicionantes e barreiras diversas, controlando e limitando $\mathrm{o}$ ingresso de produtos em seus países e em outros mercados controlados.

Nesse cenário emerge, no Brasil, o debate de políticas inclusivas na agropecuária, ganhando espaço após a Constituição Federal de 1988 (CF/1988), em paralelo às teses da Comissão Econômica para a América Latina e o Caribe (Cepal) sobre as dificuldades, desafios e limitaçôes do modelo de desenvolvimento do capitalismo na América Latina, com foco em emprego e produção (Cimoli et al., 2005). Em seguida, a política agrícola (Lei no 8.171/1991) incorpora aspectos desse debate, de demandas internas e reconhece heterogeneidades no meio rural.

Ainda que de forma incompleta e com maiores dificuldades que nos países ricos, e apesar de suas vantagens comparativas "dentro da porteira", o Brasil assimila parte do modelo global, abrindo mercados e aderindo à expansão e ao desenho dos itens $i$ a $v$ supracitados. Porém, nos anos 1990 presenciou-se a redução do investimento público, com menor suporte ao crédito, não priorização de infraestruturas e políticas distributivas. Nos anos 2000, o Brasil retoma medidas mais alinhadas com a presença do Estado na agricultura. Três pilares foram marcantes, a esse tempo, no desenho da agricultura no Brasil, conforme a seguir descrito. 
1) A ampliaçáo da abertura de mercados, para alguns, com a retirada de parte das barreiras via acordos no âmbito da Organização Mundial do Comércio (OMC), com estímulos da Organização das Nações Unidas para a Alimentação e a Agricultura (Food and Agriculture Organization - FAO) e de grandes players globais do setor, ampliando o horizonte dos produtos brasileiros no exterior. O crescimento da economia da China, do Oriente Médio e de outros parceiros na Ásia completa esse quadro de oportunidades.

2) A expansão da fronteira agrícola com foco na produção em larga escala, ocorrendo o deslocamento de capitais e plantas de agroindústrias para o Centro-Oeste e, ao mesmo tempo, deslocando a agropecuária com o desmatamento dos biomas Cerrado e Amazônia. $\mathrm{O}$ grande volume de capital estrangeiro e nacional foi o motor desse movimento, tendo investido em tecnologias disponíveis no plano internacional e no sistema nacional de inovaçáo tecnológica, com destaque para a Empresa Brasileira de Pesquisa Agropecuária (Embrapa).

3) O terceiro ponto que marcou esses mais de vinte anos entre os três últimos censos agropecuários foi o crescimento do discurso de inclusão social, aliado ao de preservação ambiental, e políticas para a pequena produção.

Com esse recorte, o Estado tem atuado sobre a âncora da oferta de crédito subsidiado, desde meados dos anos 1990 (Santos e Freitas, 2017; Freitas e Santos, 2017). Paralelamente, a implantaçáo da Política Nacional de Desenvolvimento Rural (PNDR), por meio do Decreto no 6.047/2007 (revogado pelo Decreto no 9.810/2019), continha atributos convergentes para as necessidades da agropecuária. No entanto, como se verá nos dados do censo de 2017, expostos nos artigos deste boletim, há dívidas de equidade de acesso a ativos produtivos (terra, tecnologias e bens de capital), além de assistência técnica e educação de qualidade no campo. Nas cinco regiôes, parte significativa da populaçáo depende de programas do governo, mesmo em estabelecimentos com produção agrícola.

Dessa forma, mesmo com a agropecuária obtendo seguidos recordes, nos anos 2000, perduram dificuldades para o alcance da sustentabilidade socioambiental, o que também ocorre nas cidades. O enfrentamento de problemas que afetam a produção também é desigual, com baixo nível de investimento em programas como os seguros agrícolas, embora a oferta de crédito tenha se elevado nos anos 2000-2013 (Freitas e Santos, 2017).

Como previsto na legislação e no reconhecimento da importância da agricultura pela sociedade, parte das políticas em curso, edificadas sobre os fundamentos dos três pilares citados, não é apenas direcionada à produção. Há nelas, também, o objetivo de reduzir a heterogeneidade estrutural (HE) e dar condiçôes para que a heterogeneidade produtiva (HP) seja decorrente de escolhas e desempenhos, e não da falta de oportunidades e equidade entre os produtores, sendo importante que sejam rotineiramente avaliadas.

Entre as açôes do Estado, nesse período de três décadas, destacam-se algumas que retratam a arena de disputa por recursos e por medidas de inserção produtiva, tais como: i) a criação do Ministério do Desenvolvimento Agrário e do Desenvolvimento Social (MDA), extinto em 2019; ii) a criação do Pronaf, que em 2006 foi alçado formalmente ao status de política; ${ }^{5}$ iii) o fortalecimento de sistemas de reduçáo de riscos à produção agropecuária; iv) a estruturação e a modernização dos sistemas de vigilância, inspeção e fiscalização para a defesa agropecuária; e v) a estruturação de programas para a agricultura sustentável, como o

5. A Lei oㅜ 11.326/2006 (Lei da Agricultura Familiar) foi regulamentada pelo Decreto 끄 9.064, de 31 de maio de 2017, com restrições quanto ao enquadramento do público-alvo da política, que antes tinha natureza jurídica precária. 
Programa Agricultura de Baixo Carbono e ações de apoio à agroecologia. O setor privado, por sua vez, desenvolveu um forte avanço organizativo, tecnológico e comercial em cadeias produtivas curtas e longas, com a agroindústria suprindo a demanda interna e gerando grande excedente para o exterior.

Em seu conjunto, as políticas têm dado respostas aos três pilares antes mencionados (de ampliação de mercados, de expansão da agropecuária e sua diversificação e da inclusão social). Além desses pontos, a integração produtiva da rede de commodities e cadeias longas (soja-milho-aves, suínos, cana-de-açúcar-etanol, entre outras) deu suporte a um grande aprendizado empresarial e de cooperativas que configuram as sólidas bases do setor. Com isso, cresceu a competitividade, com elevação da produtividade também para a pequena produção, em razão de ser essa uma condição primeira de acesso a grandes mercados, em que se exigem produtos padronizados.

Por fim, cabe o registro de que, embora a análise de dados seja sempre basilar para os debates e decisóes em políticas públicas, é sempre da mais alta importância que se compreenda quais teorias, ou pelo menos seus elementos estruturantes, sustentam as políticas de um determinado período e contexto social, político, econômico, ou cultural em que se vive. Ademais, a influência dos acordos e tratados internacionais sobre a agricultura e meio ambiente, a produção sustentável, bem como a criação de fundos de apoio a pesquisas e inovaçôes são outras variáveis que também influenciaram a produção agrícola e suas políticas desde os anos 1980 (Lowe, Buller e Ward, 2002).

Sendo assim, apresentam-se a seguir algumas definiçōes-chave nas quais se fundamentaram as políticas públicas e programas federais para a agricultura nas últimas três décadas desde a $\mathrm{CF} / 1988$. As definições selecionadas são aquelas que mais fortemente se relacionam com as análises sobre HE, HP, pluriatividade, multifuncionalidade e diversidade na agricultura e no ambiente rural. Essas definiçôes são retomadas em alguns artigos desta publicação.

\section{DEFINIÇÕES E CONCEITOS DE SUPORTE PARA AS POLÍTICAS VIGENTES}

\subsection{Agricultura (ou agropecuária) e suas funções no processo de desenvolvimento}

A definição de agricultura aqui adotada segue o sentido amplo e consagrado, englobando a produção vegetal em suas diversas escalas de produção, incluindo horticultura, florestas e pastagens plantadas ou manejadas com cultivos e outros (como o cultivo de cogumelos - do reino fungi -, de temperos e produção em estufas). Essa interpretação guia-se, da mesma forma que em outros autores, pela definição de agricultura adotada nos países de línguas inglesa e francesa (Wedekin, 2019, p. 21). A produção animal, denominada pecuária, inclui toda a atividade de criação de bovinos, ovinos, caprinos, equinos, bem como a pesca com manejo e aquicultura, apicultura, entre outros.

O termo agropecuária abrange os dois anteriores, referindo-se às atividades de produção de alimentos "dentro da porteira", ou seja, nos estabelecimentos agropecuários. Dessa forma, nas contas nacionais ou regionais e na Classificação Nacional de Atividades Econômicas (CNAE), por exemplo, a definição de agropecuária se refere à primeira etapa das cadeias de produção de alimentos. Portanto, o uso do termo agricultura, neste artigo, tem o mesmo significado de agropecuária, a menos que especificada uma abrangência menor.

Para além desse limite, os estabelecimentos e as atividades dos agricultores extrapolam o sentido puramente produtivo, em razão da sua multifuncionalidade, pluriatividade e da 
contribuição que emprestam ao desenvolvimento regional. Essa discussão está relacionada ao que se denomina comumente de "funçôes da agricultura", em uma visão ampliada que procura associar aspectos do desenvolvimento rural às interaçôes com o meio ambiente.

O debate tem apontado cinco funçôes da agricultura, compiladas, por exemplo, por Ramos (2007), Bonnal, Cazella e Maluf (2008), Silva (2015), conforme listadas nas primeiras linhas do quadro 1 . Além dessas, acrescentamos três outras funções, que são atualmente vivenciadas na agricultura brasileira e em outros países: i) dar respostas de sustentação das distintas formas de apossamento e usos da terra; ii) exercer funçáo de complementaridade de distintos modos de vida rural, que dependem da agricultura e vão além dela; e iii) interagir com o apelo da sustentabilidade socioambiental das atividades produtivas. As características derivadas dessas três funçôes e a situação atual delas ilustram o conjunto de movimentos, competências e avanços na agricultura no Brasil. Apenas parte desses elementos é abordada neste texto.

\section{QUADRO 1}

Funções (idealizadas e vivenciadas) da agricultura no Brasil (2019)

\begin{tabular}{|c|c|c|}
\hline Funções da agricultura & Principais características & Características derivadas e situação atual \\
\hline $\begin{array}{l}\text { 1) Provisão de alimentos e } \\
\text { matérias-primas }\end{array}$ & $\begin{array}{l}\text { O Brasil alcançou autossuficiência } \\
\text { em todos os tipos de alimentos } \\
\text { considerando-se os valores nutricionais. }\end{array}$ & $\begin{array}{l}\text { Importaç̧̃̃es como as de trigo, frutas e outros produtos } \\
\text { ocorrem naturalmente, em função de costumes e razões } \\
\text { de mercado. Há substitutos locais para todos. No Brasil, os } \\
\text { preços dos alimentos estão entre os mais baixos do planeta. }\end{array}$ \\
\hline $\begin{array}{l}\text { 2) Geração e ampliação } \\
\text { de divisas }\end{array}$ & $\begin{array}{l}\text { Produto interno bruto (PIB) } \\
\text { agroindustrial em expansão no Brasil, } \\
\text { com saldo positivo crescente na balança } \\
\text { comercial. A inserção internacional } \\
\text { é histórica com commodities (ciclos } \\
\text { madeira, açúcar, café, soja e carnes). }\end{array}$ & $\begin{array}{l}\text { Complexos soja-milho-carnes ganham mercados após } \\
\text { 1990. Em 2019, o agronegócio (agricultura + agroindústria } \\
\text { e serviços) alcançou R } \$ 1,55 \text { trilhão ( } 21,4 \% \text { do PIB), } \\
\text { ocupando mais de um quarto da mão de obra e com saldo } \\
\text { na balança comercial de US\$ } 83 \text { bilhões. Os demais setores } \\
\text { tiveram deficit de US\$ } 36 \text { bilhões. }\end{array}$ \\
\hline $\begin{array}{l}\text { 3) Transferência de capital } \\
\text { para outros setores }\end{array}$ & $\begin{array}{l}\text { Saldos de derivados da cana-de-açúcar, } \\
\text { café e outros produtos financiaram o } \\
\text { surgimento da indústria. Em seguida, } \\
\text { soja, milho, carnes e processados } \\
\text { viabilizam segmentos industriais. }\end{array}$ & $\begin{array}{l}0 \text { impulso dado pela agroindústria com a demanda de } \\
\text { novos equipamentos e tecnologias, além de abastecer } \\
\text { o mercado interno, tem possibilitado ganho de novos } \\
\text { mercados de máquinas e insumos. }\end{array}$ \\
\hline $\begin{array}{l}\text { 4) Ampliação do } \\
\text { mercado interno de } \\
\text { insumos e de setores } \\
\text { produtivos vinculados }\end{array}$ & $\begin{array}{l}\text { Desde os anos } 1960 \text { há no Brasil } \\
\text { produção em larga escala de } \\
\text { fertilizantes, máquinas e implementos } \\
\text { agrícolas. Nos anos } 1990 \text { amplia-se a } \\
\text { produção de sementes e agrotóxicos. }\end{array}$ & $\begin{array}{l}\text { Indústrias nacionais e cooperativas têm parte do mercado } \\
\text { interno de insumos, embora o domínio tecnológico e } \\
\text { econômico seja de estrangeiras e subsidiárias. Pequena } \\
\text { parte de insumos é exportada, havendo importação de } \\
\text { baixa e alta tecnologia. O Brasil possui instituições de } \\
\text { pesquisas e capacidades tecnológicas competitivas na área. }\end{array}$ \\
\hline $\begin{array}{l}\text { 5) Liberação de mão de obra } \\
\text { para outros setores }\end{array}$ & $\begin{array}{l}\text { Destaque para o período pós-1950 até } \\
\text { os anos } 1990 \text { com a mecanização e o } \\
\text { uso de insumos industriais. }\end{array}$ & $\begin{array}{l}\text { A tradição de residência no campo persiste, reduzindo, } \\
\text { desde meados dos anos 1990, o fluxo campo-cidade. } \\
\text { A população ocupada no campo no Brasil permanece } \\
\text { em torno de } 30 \text { milhões de pessoas, em parte devido à } \\
\text { pluriatividade e à multifuncionalidade. }\end{array}$ \\
\hline $\begin{array}{l}\text { 6) Lócus e fase da } \\
\text { apropriação da natureza } \\
\text { e de acumulação como } \\
\text { "capital natural" }\end{array}$ & $\begin{array}{l}\text { A apropriação de terras e de seus } \\
\text { recursos é praticada desde antes da } \\
\text { produção capitalista. Contudo, sua } \\
\text { mercantilização persiste como função } \\
\text { de acumulação. }\end{array}$ & $\begin{array}{l}\text { A posse e o acesso à terra mantêm as formas de aquisição } \\
\text { (ocupação, grilagem, compra, aluguel) com mudanças nas } \\
\text { formas de domínio (por títulos de posse ou por contratos e } \\
\text { garantias dos agentes das cadeias de valor). }\end{array}$ \\
\hline $\begin{array}{l}\text { 7) Suporte e reprodução } \\
\text { de modos de vida, } \\
\text { culturas, costumes e } \\
\text { interações interdisciplinares }\end{array}$ & $\begin{array}{l}\text { Essa é a mais antiga função da } \\
\text { agricultura, base da evolução das } \\
\text { sociedades. Ela se manifesta de } \\
\text { diferentes formas, com adaptações nas } \\
\text { regiões e países. }\end{array}$ & $\begin{array}{l}\text { Retrata os agricultores pluriativos, suas multifunções e } \\
\text { a reprodução de suas condições de vida, embora não } \\
\text { totalmente alinhadas ao modo de produção capitalista. } \\
\text { Relaciona-se com as características regionais e dos biomas. }\end{array}$ \\
\hline $\begin{array}{l}\text { 8) Lócus de interações } \\
\text { entre atividades produtivas } \\
\text { e a sustentabilidade } \\
\text { socioambiental }\end{array}$ & $\begin{array}{l}\text { Atividade naturalmente geradora } \\
\text { de impactos ambientais, tanto } \\
\text { de danos como de contribuições } \\
\text { conservacionistas e de cunho inclusivo } \\
\text { social e ambientalmente. }\end{array}$ & $\begin{array}{l}\text { São desenvolvidas atividades que substituem o extrativismo } \\
\text { e danos diretos às florestas (como cana-de-açúcar e } \\
\text { madeira plantada com redução da emissão de carbono). } \\
\text { No entanto, contaminantes impactam o solo e a água, } \\
\text { gerando externalidades com custos sociais. }\end{array}$ \\
\hline
\end{tabular}

Fonte: Ramos (2007); Bonnal, Cazella e Maluf (2008); e Silva (2015).

Elaboração dos autores. 


\subsection{Agricultura familiar}

O conceito de agricultura familiar procura sinalizar uma forma de olhar para as atividades praticadas no meio rural por um ângulo não apenas produtivista. Reconhece no agricultor de pequeno porte funçóes mais amplas que a produção de alimentos, sendo os estabelecimentos também o local de moradia dos proprietários, os quais empregam membros da família. Nessa condição, ela se estrutura a partir de instrumentos de política pública que a fortalecem em todos os elos da cadeia produtiva e, principalmente, por sua grande resiliência. ${ }^{6}$

A definição do termo agricultura familiar é peculiar para o caso do Brasil, tendo sofrido mudanças ao longo dos anos. Sua origem remonta à convivência da família, moradora e proprietária da terra e dos meios de produção (ou ocupante, arrendatário, mesmo em situação precária), que exerce atividades produtivas no estabelecimento rural em que reside. Segundo a Lei oํ 11.326/2006, regulamentada pelo Decreto oㅜ 9.064/2017, a agricultura familiar é aquela que possui, a qualquer título, área de até quatro módulos fiscais, utiliza, no mínimo, metade da força de trabalho familiar no processo produtivo e de geração de renda, aufere, no mínimo, metade da renda familiar de atividades econômicas do seu estabelecimento ou empreendimento e tem gestão estritamente familiar. Essa categoria de agricultores corresponde a 76,8\% do total dos agricultores no Brasil, de acordo com o Censo Agropecuário 2017 (IBGE, 2019).

Para efeitos de políticas públicas, os silvicultores, aquicultores, extrativistas, pescadores, povos indígenas e quilombolas (e, a definir, "demais povos tradicionais") podem ser elegíveis a público-alvo das açôes do Estado e das políticas para agricultura familiar, se cumpridas todas as exigências.

Embora o aspecto central da definição remeta ao entendimento de que a agricultura familiar no Brasil está diretamente ligada ao tamanho da propriedade, cabe registrar que o módulo fiscal tem tamanhos distintos conforme as regióes, biomas e municípios, variando de 5 ha (na regiáo Sudeste, por exemplo) a 110 ha (na Amazônia). Assim, segundo Del Grossi et al. (2019, p. 43), "em 2006 mais de 541 mil pequenos produtores não foram classificados como agricultores familiares (AF), número que aumentou para $853 \mathrm{mil} \mathrm{em}$ 2017". Isso ocorre em razão de os estabelecimentos não atenderem a algum dos requisitos da Lei no 11.326/2006. Por sua vez, o termo agricultura comercial, ou "não familiar" no Brasil, é todo estabelecimento com produção agrícola excedente ao consumo próprio que não se enquadra na definiçâo de agricultura familiar.

\subsection{Agronegócio}

O termo agronegócio tem origem em 1957, segundo Wedekin (2019), advindo de estudiosos dos Estados Unidos e de outros países, com referência ao termo agrobusiness, criado pelo professor Ray Goldberg na década de 1950 (Rust, Davis e Goldberg, 1957), para agregar todas as atividades produtivas que se ligam à agropecuária, desde a produção de insumos e máquinas, passando pelas atividades da fazenda e chegando à agroindústria processadora e daí até ao consumidor final. Portanto, o conceito é baseado nos encadeamentos produtivos

6. Observando as interpretações clássicas da teoria do desenvolvimento agrícola no capitalismo, Baiardi e Alencar (2014) tratam da resiliência e da adaptabilidade da agricultura familiar em algumas das regiões e biomas. Destacam que esses dois fatores fazem os agricultores familiares ligarem-se ao mercado de produtos e insumos e à estrutura produtiva, mantendo laços com a indústria e relacionando-se com a grande agricultura capitalista. Segundo os autores, o grande problema é a baixa perspectiva de prosperidade para a maioria dos pequenos produtores familiares, em grande parte residentes na região do Semiárido no Nordeste. 
e se diferencia de agropecuária, não sendo a ele aplicáveis aspectos de propriedade, escala, uso de tecnologia, e sim a análise do fluxo de insumos e mercadorias. A definição-chave é a comercialização de produtos agrícolas, além de pressupor o armazenamento e etapas da distribuição em grande escala (exceto vendas de varejo).

Do ponto de vista quantitativo e dos componentes, o produto total do agronegócio (PIB Agro), no Brasil e em outros países, resulta de toda a produção da agricultura, pecuária e seus insumos, semiprocessados e processados de alimentos, de bioenergia, insumos destinados a demais cadeias (como tecidos, madeira, celulose e papel, couros, fibras, sisal, capins, sementes) e outros (Santos, 2014; Cepea, 2017). ${ }^{7}$ Assim, o PIB Agro inclui todo o produto dos agricultores familiares e não familiares.

Outro significado que se consagra no Brasil a respeito do agronegócio é, simplesmente, o que não é alcançado pela definição de agricultura familiar, sendo associado ao grande empreendimento agrícola primeiramente voltado para a realização de lucro. Ao mesmo tempo, cadeias agroindustriais como as do arroz, tomate/condimentos, soja-milho-aves, frutas e outras são ofertantes de alimentos a baixos preços relativos ao meio urbano e rural, em razão de tecnologias, larga escala, sistemas de produção, estoque e comercialização altamente competitivos.

\subsection{Segurança alimentar}

O termo segurança alimentar tem estado cada vez mais presente nas políticas públicas no Brasil e no plano global. Destacam-se as iniciativas da FAO e os acordos internacionais, como os Objetivos do Milênio e os Objetivos de Desenvolvimento Sustentável (ODS), também da Organização das Nações Unidas (ONU), dos quais o Brasil tem sido signatário. Internamente, a Lei no 11.346/2006 criou o Sistema Nacional de Segurança Alimentar e Nutricional (Sisan), que estabelece:

Art. $2^{\circ} \mathrm{A}$ alimentação adequada é direito fundamental do ser humano, inerente à dignidade da pessoa humana e indispensável à realização dos direitos consagrados na Constituição Federal, devendo o poder público adotar as políticas e açôes que se façam necessárias para promover e garantir a segurança alimentar e nutricional da população.

Essa lei criou o Conselho Nacional de Segurança Alimentar (Consea) e estabeleceu que o Estado e suas políticas devem observar aspectos como biodiversidade, meio ambiente, saúde, cidadania, entre vários outros. A definição trazida pela lei incorpora o que se consolida de mais avançado no tema no plano internacional (Lei no 11.346/2006):

Art. $3^{\circ}$ A segurança alimentar e nutricional consiste na realização do direito de todos ao acesso regular e permanente a alimentos de qualidade, em quantidade suficiente, sem comprometer $\mathrm{o}$ acesso a outras necessidades essenciais, tendo como base práticas alimentares promotoras de saúde que respeitem a diversidade cultural e que sejam ambiental, cultural, econômica e socialmente sustentáveis.

Além disso, a norma traz também diretrizes como acesso e priorização do uso da água, armazenamento e formaçáo de estoques de alimentos, foco nos mais vulneráveis e necessidade de coordenação e integração de políticas com participação social nas decisóes sobre o tema.

7. Santos (2014) nomina por CNAEs as classificações incluídas, revelando que o setor representa 22,5\% do PIB Brasil. 0 Centro de Estudos Avançados em Economia Aplicada (Cepea) registrou, em 2017, o PIB Agro de R\$ 1,55 trilhão; manteve essa mesma ordem de grandeza em 2018 e passou de R\$ 1,6 trilhão em 2019, equivalente a 22\% do PIB Brasil no ano. 
O Brasil, em 2014, contava ainda com o Índice de Insegurança Alimentar abaixo de 5\%, deixando de figurar no Mapa da Fome da FAO.

\subsection{Segurança dos alimentos}

Este conceito se refere à qualidade dos alimentos em todas as suas etapas de produção até o consumidor. As políticas de segurança dos alimentos são baseadas em critérios como o códex alimentar, as certificações de alimentos e a rastreabilidade.

Os países desenvolvidos estão utilizando essas políticas atualmente para pautar - e até mesmo impor barreiras à entrada de produtos agrícolas - desde os critérios de comércio até parâmetros de produção, respeito às normas ambientais, saúde animal e normas de comercialização de alimentos. No Brasil, esse conceito ainda é pouco relacionado com as políticas públicas de alimentação.

\subsection{Multifuncionalidade da agricultura familiar}

A noção de multifuncionalidade da agricultura se relaciona, segundo Wanderley (2003a; 2003b) e Silva (2015), com o desenvolvimento territorial para além da produção agrícola e com as formas de reprodução social, de manutenção de valores e opçôes da família de agricultores e de sua interação com a natureza e a sociedade. Carneiro e Maluf (2003) e Bonnal, Cazella e Maluf (2008) consideram que a multifuncionalidade da agricultura familiar ultrapassa o caráter setorial, alcançando funçôes sociais ligadas às famílias rurais, ao território e ao seu entorno social. Silva (2015) considera a agricultura familiar como categoria inserida no contexto do desenvolvimento territorial sustentável e de políticas públicas que devem transferir benefícios aos agricultores.

Carneiro e Maluf (2003) e Bonnal, Cazella e Maluf (2008) destacam quatro funçôes da agricultura familiar, que, resumidamente, seriam: i) reprodução socioeconômica das famílias; ii) promoção da segurança alimentar da sociedade e das próprias famílias rurais; iii) manutenção do tecido social e cultural; e iv) preservação dos recursos naturais e da paisagem rural. Atualmente, outras correntes interpretativas estendem tais funçôes como inerentes a todos os modelos e portes da agricultura, sejam eles menos ou mais voltados para a grande produção. Esse enfoque muda o conceito puramente econômico e as funçóes da agricultura.

Entre as políticas, programas e açôes que se relacionam a esse conceito estão: a PNDR; açôes de eletrificação rural como o Luz para Todos e a Tarifa Social de Energia Rural; o Pronaf em toda sua amplitude; o Programa de Aquisição de Alimentos (PAA); o Fundo Garantia Safra e o Benefício Garantia Safra; açóes pró-Política Nacional de Assistência Técnica e Extensão Rural (PNATER); ajustes no Programa de Garantia da Atividade Agropecuária (Proagro); o Programa Nacional de Alimentação Escolar (PNAE); o Programa Cisternas; instrumentos de apoio à comercialização e preços mínimos; e programas de transferência de renda, como o Bolsa Família.

\subsection{Pluriatividade da agricultura e dos estabelecimentos agrícolas}

Marques (1995) e Mattei (1999) relatam diferentes modelos de pluriatividade estudados na Europa e no Brasil. As famílias e os estabelecimentos pluriativos "passam a combinar as atividades agrícolas com as atividades não agrícolas, tanto interna como externamente às propriedades" (Mattei, 1999, p. 7). Esses autores notam diferenças em fatores que moldam as distintas pluriatividades: estruturas fundiárias (mini, pequenas e grandes propriedades); 
desigualdade na aplicação de recursos de políticas; mudanças na produtividade agrícola, excedente de máo de obra; interaçốes com centros urbanos; desenvolvimento dos complexos agroindustriais; verticalização da produção etc. Vários fatores levam à pluriatividade, nas dimensóes social, econômica, pessoal e contextual. O conceito de pluriatividade, portanto, enxerga a exploração agropecuária como um espaço de produçáo e geração de renda diversificado.

Segundo Schneider (2003a) e Schneider et al. (2013), a pluriatividade expressa a multifuncionalidade da agricultura em atividades náo agrícolas geradoras de renda. São exemplos a agroindústria, o agroturismo e a comercialização direta. A dedicação de parte do tempo dos trabalhadores na propriedade e parte fora é característica da pluriatividade. É ilustrativa a definição de Schneider et al. (2013, p. 17) para estabelecimentos pluriativos, para fins de busca e análise de dados:

estabelecimento pluriativo é aquele estabelecimento agropecuário em que o produtor e/ou algum membro da família exerceu atividades agropecuárias e algum tipo de atividade não agropecuária remunerada e/ou qualquer tipo de atividade remunerada fora do estabelecimento.

Schneider (2003b) destaca que esse tema tem sido objeto de estudo da sociologia e economia agrária desde o início do século XX. Segundo o autor, Lenin considerava que, mesmo com a multirrenda, haveria desintegração da pequena produção, a semiproletarização dos agricultores, pelo que ela sucumbiria à propriedade padrão do capital, que é mais produtiva. Por sua vez, Alexander Chayanov, em oposição a Lenin, defendia a persistência da pequena agricultura, sendo a multirrenda um fator importante. A visão de Chayanov deu vazão, no caso do Brasil (Kageyama, 1998; 2004; Abramovay, 1992; Schneider, 2003b; Schneider et al., 2013), a que houvesse espaço e não linearidade nas soluçôes da pequena agricultura, sendo moldadas políticas nesse sentido a partir da CF/1988. ${ }^{8}$

Por estarem relacionadas, algumas das políticas, programas e açôes que fomentam o conceito de multifuncionalidade também dão suporte à pluriatividade, por exemplo: açóes de eletrificação rural, a Tarifa Social de Energia Rural; o Pronaf em alguns componentes; o PAA; e o PNAE. Além dessas, as políticas que facilitam a moradia no campo e a divisão do tempo dedicado ao trabalho na agricultura com outras atividades dentro e fora do estabelecimento também ajudam os agricultores pluriativos, ${ }^{9}$ como o fomento a agroindústrias rurais, o crédito subsidiado à produção, o apoio à construção de moradias no campo, o Programa Garantia Safra (socorro nos casos de secas) e programas de transferência de renda.

\subsection{Heterogeneidade estrutural}

$\mathrm{Na}$ agricultura, a análise da heterogeneidade demanda observaçóes sobre o médio e o longo prazos, como assinalado em Santos e Vieira Filho (2012) e em Vieira Filho, Santos e Fornazier (2013), e devem ser observadas diferenças produtivas que extrapolam a diversidade natural da produção capitalista. A característica central da HE na agricultura "está ligada às disparidades estáticas, que não dependem apenas da melhor alocação de fatores em um mercado de livre concorrência" (Vieira Filho, Santos e Fornazier, 2013, p. 10). Os autores mencionam, entre os fatores que levam à HE: "a disponibilidade de água para irrigação, a

8. No Brasil, esse debate surge também como resposta a demandas sociais, com o apoio da Igreja Católica, de movimentos de trabalhadores sem-terra e de organizações como a Confederação Nacional dos Trabalhadores na Agricultura (Contag), configurando as políticas em apoio ao que veio a se denominar agricultura familiar.

9. Schneider et al. (2013) detalham os diversos tipos de pluriatividade presentes no campo, no Brasil de base agrária; para-agrícola; e intersetorial, todos mantendo ocupação parcial dos agricultores/trabalhadores no meio rural. 
infraestrutura de escoamento da safra e as condiçôes de acesso às tecnologias de produçáo" (idem, ibidem).

De acordo com Cepal (2010a; 2010b) e Nohlen e Sturm (1982), a heterogeneidade (no caso incluem HE e HP) está relacionada tanto às condiçóes de produção e consumo domésticos quanto a fatores externos como a interdependência de mercados, trajetórias tecnológicas e termos de troca. No caso do Brasil, acrescentam-se fatores estáticos regionais como relevo, tipo de solo e clima e baixa disponibilidade de água, como abordado em Santana e Santos (2020), como fator estrutural determinante das diferenças produtivas e de heterogeneidades na região do Semiárido nordestino, em razão da longa estiagem de 2012 a 2017.

Outros fatores de igual importância na HE devem ser considerados, como tem sido abordado na literatura: o tamanho e recursos de partida da propriedade rural (fator que limita o que se pode fazer, em que escala e a que custo de tecnologia); e as condiçóes de operação para se posicionar em mercados (caso de condicionantes ou barreiras de acesso às políticas de crédito, seguros, assistência técnica etc., a exemplo da baixa capacidade de endividamento e de inexistência de garantias nos casos de minifúndios). Para Furtado (1964), a HE na agricultura brasileira decorreu de uma separaçáo de posicionamentos entre a grande propriedade voltada para a exportaçáo e a agricultura voltada para o mercado interno, ficando esta última com baixo incentivo financeiro.

Cabe observar que as abordagens acerca da $\mathrm{HE}$ e as políticas a ela relacionadas devem ter em conta que a diversidade de dotação de fatores é natural na agricultura, e não é possível ter a mesma padronização que há no segmento industrial. Desse modo, as políticas e seus instrumentos podem falhar no tocante às especificidades locais e regionais, uma vez que são desenhadas para dar respostas a questôes guiadas pelo mercado e não à diversificação ou à promoção de mercados locais de alimentos.

Entre iniciativas relacionadas à $\mathrm{HE}$ no meio rural destacam-se: políticas de acesso e manutenção de ativos (como componentes do Pronaf, Fundo Garantia Safra, Programa Nacional de Reforma Agrária ou de distribuição de terras); açóes para infraestrutura na PNDR; açôes para a qualidade de vida no campo (eletrificação rural e tarifa social de energia); e infraestrutura em geral (inclusive de apoio à produção e à armazenagem, acesso à água para consumo e produção, construção de moradias, unidades agroindustriais, escolas, atenção à saúde, pavimentação de estradas vicinais, regularização de terras, cadastros etc.). Pode-se observar que nessa lista resumida estão iniciativas relacionadas também com a HP ou com a multifuncionalidade e pluriatividade da agricultura por estarem imbricadas.

\subsection{Heterogeneidade produtiva}

A HP na agricultura, também como definida em Vieira Filho, Santos e Fornazier (2013, p. 10), é "a persistência de profundas diferenças dos resultados da atividade econômica dos estabelecimentos (nível de produção, valor adicionado e renda líquida)". De acordo com os autores, "as questôes estruturais condicionam a heterogeneidade produtiva, entretanto nem sempre diferenças produtivas representam heterogeneidade estrutural" (idem, ibidem). Em outras palavras, espera-se que existam graus distintos de produtividade (do trabalho e total dos fatores) que se devem aos diferentes modos de produção, ao comportamento, a opçôes ou trajetórias de desenvolvimento específicas de estabelecimentos, ainda que dentro das mesmas localidades e regiôes, ou em grupos de produtores semelhantes e comparáveis entre si. 
Essas diferenças de produtividade são compreensíveis em diversos sistemas produtivos, inclusive na agricultura. Quando elas se prolongam no tempo, caracteriza-se a HP. A análise de indicadores é necessária para identificar até que ponto a HE está vinculada ou induz à HP, e qual o tipo de política pública pode ser implementada, seja para reduzir em parte a HE e a HP, seja para recepcionar a diversidade a elas relacionada.

$\mathrm{Na}$ análise da heterogeneidade, seja ela HE ou HP, é importante observar, de acordo com Santos e Vieira Filho (2012) e Silva (2015), a abrangência geográfica, além da setorial, para analisar variáveis, criar índices a fim de retratar as disparidades e identificar fatores a aperfeiçoar. Isso envolve o apoio às atividades produtivas, a facilitação da organização produtiva, a gestão e o desenvolvimento de cooperativas, assistência técnica, difusão e incentivo à adoção de tecnologias, além do acesso aos sistemas de financiamento. Ademais, o estudo da heterogeneidade na agricultura deve considerar a diversidade dos sistemas produtivos, e não apenas dos produtos, além das características dos mercados nos quais eles se inserem.

Deve-se acrescentar que a HP pode estar relacionada com a racionalidade dos agentes produtivos, suas escolhas tecnológicas e de inserção no mercado. Nessa situaçáo, a HP é natural na agricultura, desde que não se confunda com as consequências da $\mathrm{HE}$ e de posicionamentos não dinâmicos dos produtores (por exemplo, entre produtores que cumprem e aqueles que não cumprem a lei ambiental e têm vantagens espúrias, portanto).

As iniciativas do poder público voltadas para a HP são tipicamente medidas setoriais como produção ambientalmente sustentável, defesa e controle sanitário, pesquisa e inovação tecnológica e da gestão, apoio à redução de riscos, zoneamento agrícola, difusão tecnológica e extensão rural. Medidas que alcançam os sistemas de produção de insumos, promovem a comercialização e dão suporte ao cooperativismo podem ser incluídas nesse rol.

\section{OUTRAS CONSIDERAÇÕES SOBRE A DIVERSIDADE DA AGRICULTURA BRASILEIRA}

Os conceitos e definiçóes apresentados até aqui ilustram como a diversidade é natural do meio rural e da agricultura. No Brasil, ela reflete a pluralidade e aspectos do desenvolvimento regional e seus desafios. A diversidade em seu recorte produtivo remete a dois aspectos básicos: i) que há variedade de produtos na mesma propriedade agrícola, podendo ter significância para consumo próprio como também para a comercialização; e ii) que há distintos sistemas de produção agrícola (rotas tecnológicas, tipos de inserção no mercado, voltados para a concorrência e a comercialização ou para subsistência) ou mesmo variados usos não agrícolas da terra (ecoturismo, casa de campo com pequena produçáo ou mesmo residência rural de ocupados do meio urbano), somando pluriatividade e multifuncionalidade.

A diversidade na agropecuária remete, portanto, aos conceitos de multifuncionalidade e pluriatividade, sendo fortemente associada à agricultura familiar, mas não somente a ela. Embora as condiçóes de acesso aos ativos e infraestruturas, por parte de produtores capitalizados, levem à monocultura e a agroindústrias de grande porte, seja o referencial antagônico à pluriatividade e à multifuncionalidade, nada impede que grandes estabelecimentos tenham diversidade na variedade de produtos, como nos casos da adoção da integração lavoura-pecuária-floresta (ILPF). A diversidade pode ocorrer, ainda, em distintas escalas, ou em situaçôes que possibilitam pequenos cultivos, inclusive a arrendatários/meeiros de grandes fazendas. 
Diante da atual crise fiscal do Estado, do estágio de desenvolvimento que a agricultura alcançou, e das dificuldades e desafios ainda existentes, levantamos a hipótese da necessidade de se mudar a visão teórica que fundamenta as políticas públicas agrícolas em suas diversas fases. Como um primeiro passo, cabe deixar questóes que fomentam essa hipótese, dado o espaço disponível: analisar como a teoria que dá suporte às políticas incorpora as mudanças de foco da propriedade monocultora para a diversificada; e estudar como tal teoria transita (se transita) da visão disciplinar para a interdisciplinar.

O conjunto de funçôes da agropecuária é suficiente para induzir uma pluralidade de teses, hipóteses e sugestóes de políticas tendo como ponto de partida questôes como essas e outras a respeito de realidades que estudiosos e governos devem se debruçar.

\section{REFERÊNCIAS}

ABRAMOVAY, R. Paradigmas do capitalismo agrário em questáo. São Paulo: Hucitec, 1992.

BAIARDI, A.; ALENCAR, C. M. M. Agricultura familiar, seu interesse acadêmico, sua lógica constitutiva e sua resiliência no Brasil. 2015. RESR. Piracicaba, SP, v. 52, p. 45-62, 2014. Supl. 1.

BELIK, W. A heterogeneidade e suas implicaçôes para as políticas públicas no rural brasileiro. Revista de Economia e Sociologia Rural. Piracicaba, SP, v. 53, n. 1, p. 9-30, jan./mar. 2015.

BONNAL, P.; CAZELLA, A. A.; MALUF, R. S. Multifuncionalidade da agricultura e desenvolvimento territorial: avanços e desafios para a conjunção de enfoques. Estudos Sociedade e Agricultura. Rio de Janeiro, v. 16, n. 2, p. 185-227, 2008.

CARNEIRO, M. J.; MALUF, R. Para além da produçáo: multifuncionalidade e agricultura familiar. Rio de Janeiro: Nead/UFRJ, 2003.

CEPAL - COMISSÁO ECONÔMICA PARA A AMÉRICA LATINA E O CARIBE. A hora da igualdade: brechas por selar, caminhos por abrir. Trigésimo terceiro período de sessóes da Cepal. Brasília, 30 maio/1o jun. 2010a.

Heterogeneidad estructural y brechas de productividad: de la fragmentación a la convergencia. Santiago: Cepal, cap. 3, p. 91-129, 2010 b.

CEPEA - CENTRO DE ESTUDOS AVANÇADOS EM ECONOMIA APLICADA. Metodologia - PIB do agronegócio brasileiro: base e evolução. Piracicaba, SP: Cepea/Esalq/ USP, 2017. 26 p. Disponível em: <https://www.cepea.esalq.usp.br/upload/kceditor/files/ Metodologia\%20PIB_divulga\%C3\%A7\%C3\%A3o.pdf>. Acesso em: 20 jul. 2020.

Índice Exportaçáo do Agronegócio. 2019. Disponível em: <https://www.cepea.esalq. usp.br/upload/kceditor/files/Cepea_ExportAgro_2019_.pdf>. Acesso em: 20 mar. 2020.

CIMOLI, M. et al. Cambio estrutural, heterogeneidade productiva y tecnología en América Latina. Santiago de Chile: Cepal/BID, 2005.

COSTA, F. A. Trajetórias tecnológicas como objeto de política de conhecimento para a Amazônia: uma metodologia de delineamento. Revista Brasileira de Inovaçáo, v. 8, n. 1, p. 287-312, 2009.

DEL GROSSI, M. et al. Comunicação de pesquisa: delimitando a agricultura familiar nos censos agropecuários brasileiros. Revista Necat, v. 8, n. 16, p. 40-45, jun./dez. 2019.

FAO - FOOD AND AGRICULTURE ORGANIZATION OF THE UNITED NATIONS; UNEP - UNITED NATIONS ENVIRONMENT PROGRAMME. The State of the World's

Forests 2020. Forests, biodiversity and people. Roma: FAO, 2020. Disponível em: <http:// www.fao.org/documents/card/en/c/ca8642en>. Acesso em: 19 jul. 2020. 
FREITAS, R. E.; MACIENTE, A. N. Requerimentos típicos de mão de obra agrícola. Radar da Tecnologia, Produçáo e Comércio Exterior, v. 45, p. 43-56, 2016.

FREITAS, R. E.; SANTOS, G. R. Crédito agrícola no Brasil: trajetória recente, desafios e oportunidades. Boletim Regional, Urbano e Ambiental, Brasília: Ipea, n. 17, jul./dez. 2017.

FURTADO, C. A dialética do desenvolvimento. Rio de Janeiro: Fundo de Cultura, 1964.

IBGE - INSTITUTO BRASILEIRO DE GEOGRAFIA E ESTATÍSTICA. Censo Agropecuário 2017. 2019. Disponível em: <https://sidra.ibge.gov.br/pesquisa/censo-agropecuario/censoagropecuario-2017>. Acesso em: 28 mar. 2019.

KAGEYAMA, A. Pluriatividade e ruralidade: aspectos metodológicos. Revista Economia Aplicada, São Paulo: USP, v. 2, n. 3, 1998.

Desenvolvimento rural: conceito e medida. Cadernos de Ciência \& Tecnologia, Brasília, v. 21, n. 3, p. 379-408, set./dez. 2004.

LOWE, P.; BULLER, H.; WARD, N. Setting the next agenda? British and French approaches to the second pillar of the Common Agricultural Policy. Journal of Rural Studies, v.18, p. 1-17, 2002.

MACHADO, A. B.; CASALINHO, H. D. Crítica à pluriatividade e suas relaçóes com o campesinato e a reforma agrária. Revista Nera, São Paulo, ano 13, n. 17, 2010.

MARQUES, H. A agricultura a tempo parcial e agricultores pluriactivos no Noroeste de Portugal. Revista da Faculdade de Letras, Geografia I, Série X/XI, v. 10, p. 39-104, 1995.

MATTEI, L. Pluriatividade e desenvolvimento rural no estado de Santa Catarina. 1999. Tese (Doutorado) - Universidade Estadual de Campinas, Campinas, 1999.

NIEDERLE, P. A.; FIALHO, M. A. V.; CONTERATO, M. A. A pesquisa sobre agricultura familiar no Brasil - aprendizagens, esquecimentos e novidades. Revista de Economia e Sociologia Rural, Piracicaba, v. 52, Supl. 1, Editorial, p. S009-S024, 2014.

NOHLEN, D.; STURM, R. La heterogeneidad estructural como concepto básico en la teoria de desarrollo. Revista de Estudios Políticos, n. 28, jul./ago. 1982.

OECD - ORGANISATION FOR ECONOMIC CO-OPERATION AND DEVELOPMENT. Agricultural policy monitoring and evaluation. 2020. Disponível em: <http://www.oecd.org/ agriculture/topics/agricultural-policy-monitoring-and-evaluation/>. Acesso em: 22 jul. 2020.

RAMOS, P. Referencial teórico e analítico sobre a agropecuária brasileira. In: (Org.).

Dimensóes do agronegócio brasileiro, Brasília: Nead, p. 18-52, 2007.

RUST, I. W.; DAVIS, J.; GOLDBERG, R. A. A concept of agribusiness. American Journal of Agricultural Economics, v. 39, n. 4, Nov. 1957, p. 1042-1045.

SAMBUICHI, R. H. A. et al. (Org.). Política Nacional de Agroecologia e Produçáo Orgânica no Brasil. Brasília: Ipea, 2017.

SANTANA, A. S.; SANTOS, G. R. Impactos da seca de 2012-2017 na regiáo semiárida do Nordeste: notas sobre a abordagem de dados quantitativos e conclusóes qualitativas. Boletim Regional, Urbano e Ambiental, Rio de Janeiro: Ipea, n. 22, 2020.

SANTOS, G. R. Agroindústria no Brasil: um olhar sobre indicadores de porte e expansão regional. Brasília: Ipea, fev. 2014. (Boletim Radar, n. 31). Disponível em: <https://www.ipea. gov.br/portal/images/stories/PDFs/radar/140226_radar31.pdf >. 
SANTOS, G. R.; FREITAS, R. E. Gasto público com a agricultura no Brasil: uma abordagem a partir de dados agregados. Boletim Regional, Urbano e Ambiental, Brasília: Ipea, n. 17, jul./dez. 2017.

SANTOS, G. R.; VIEIRA FILHO, J. E. R. Heterogeneidade produtiva na agricultura brasileira: elementos estruturais e dinâmicos da trajetória produtiva recente. Rio de Janeiro/Brasília: Ipea, 2012. (Texto para Discussão, n. 1740).

SCHNEIDER, S. Rurbanização e pluriatividade: o mercado de trabalho não-agrícola e a pluriatividade das famílias em áreas rurais. In: CARVALHO, F. M. Desigualdades sociais: pobreza, desemprego e questão agrária. Viçosa: DER/UFV, 2003a.

A pluriatividade da agricultura familiar. Porto Alegre: UFRGS, 2003b.

SCHNEIDER, S. et al. Pluriatividade e plurirrendimentos nos estabelecimentos agropecuários do Brasil e das regióes Sul e Nordeste: uma análise a partir do Censo Agropecuário 2006. Brasília: Ipea, 2013. (Relatório de Pesquisa).

SILVA, S. P. A agricultura familiar e suas múltiplas interaçóes com o território: uma análise de suas características multifuncionais e pluriativas. Rio de Janeiro: Ipea, 2015. (Texto para Discussão, n. 2076).

STEVENS. C. Agriculture and green growth. OECD, 2011. 40 p. Disponível em: <http:// www.oecd.org/greengrowth/sustainable-agriculture/48289829.pdf>. Acesso em: 22 jul. 2020.

VIEIRA FILHO, J. E. R.; SANTOS, G. R.; FORNAZIER, A. Distribuiçáo produtiva e tecnológica da agricultura brasileira e sua heterogeneidade estrutural. Brasília: Cepal, 2013. (Textos para Discussão Cepal-Ipea, n. 54). Disponível em: <https://repositorio.cepal.org/ bitstream/handle/11362/36848/1/LCBRSR277_pt.pdf>.

WANDERLEY, M. N. B. Apresentaçâo. In: CARNEIRO, M. J.; MALUF, R. Para além da produçáo: multifuncionalidade e agricultura familiar. Rio de Janeiro: Nead, 2003 a.

Agricultura familiar e campesinato: rupturas e continuidade. Estudos Sociedade e Agricultura, Rio de Janeiro, n. 21, p. 42-61, 2003 b.

WEDEKIN, I. (Org.). Política agrícola no Brasil: o agronegócio na perspectiva global. São Paulo: WDK Agronegócio, 2019.

WELLER, J. (Ed.). Brechas y transformaciones: la evolución del empleo agropecuario en América Latina. Santiago: Cepal, 2016. (Libros de la Cepal, n. 141). 
